\title{
ADAPTIVE CONTROL OF THE SCORBOT-ER 4PC MANIPULATOR
}

\begin{abstract}
The problem of the manipulator tracking control is not trivial because the manipulator is a nonlinear object, whose parameters may be unknown and variable. The control law should enable the manipulator to behave correctly even when operational conditions are changeable. The adaptive control system meets this requirement. In this paper, both kinematic and dynamic equations of motion for the Scorbot-ER $4 \mathrm{pc}$ are presented. The adaptive control algorithm was derived for this manipulator. The presented control and adaptive laws guarantee practical Lyapunov stability. The results of verification of theoretical investigations are presented. Experiments were carried out on a work station which consists of the Scorbot-ER 4pc robotic manipulator, a computer with Matlab and dSPACE ControlDesk software and a DS1006 digital signal processing board. In the experiments, the specified point of the manipulator has moved on a desired circular path and the gripper of the manipulator was loaded in variable ways. The operation of adaptive control system was compared with the computed moment method. From the result of the comparison we can see that, in practice, the adaptive control gives better results.
\end{abstract}

Keywords: robotic manipulator, manipulator's dynamics, adaptive control system, Lyapunov stability

\section{Introduction}

Robotic manipulators are devices which find different applications in many domains of the economy, for example in industry. The requirements in relation to precision and autonomy of manipulators are increasing as well as the tasks performed by them are more and more complex. The control of such complex systems is very problematic. Manipulators are objects with nonlinear dynamics, often with unknown and variable parameters which operate in changeable conditions. A change in operating conditions may result from the variation of mass and the mass moment of inertia of the objects which are carried by the gripper. The control system has to generate such control signals that will guarantee the

\footnotetext{
${ }^{1}$ Autor do korespondencji/corresponding author: Piotr Gierlak, Rzeszow University of Technology, 8 Powstańców Warszawy Avenue, 35-959 Rzeszow, Poland, tel.: (17) 8651854, e-mail: pgierlak@prz.edu.pl
} 
execution of movement along a path with desired precision in spite of the operating conditions.

In the control systems of contemporary industrial manipulators the computed torque method [1-3] for nonlinearity compensation is used. However, these approaches require precise knowledge about mathematical models of the control objects, such as the mathematical structure of motion equations with coefficients connected with geometry, mass, mass moment of inertia of links. Determining friction coefficients in kinematic pairs is especially difficult. Moreover, in such an approach, parameters in the compensator have nominal values so the control system acts without taking into account the changeable operating conditions.

In connection with the present difficulties, adaptive control techniques [1-7] were developed. These methods require a structure of mathematical models of the control objects but no parameters are needed.

\section{Description of the Scorbot-ER 4pc robotic manipulator}

The Scorbot-ER 4pc robotic manipulator is shown in fig. 1a. The manipulator has rotational kinematic pairs. It is driven by direct-current motors with gears and encoders, which allow to determine angular velocities and the angles of rotation of links. The manipulator arm has 3 degrees of freedom (DOF) whereas the gripper has $2 \mathrm{DOF}$. In this paper we modeled the gripper as discrete mass located at the end of the last link of the arm (point $C$ - see fig. 1b). In the remainder of the paper we will consider only 3 DOF of the arm.

a)

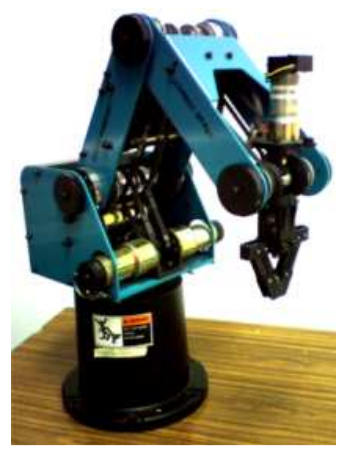

b)

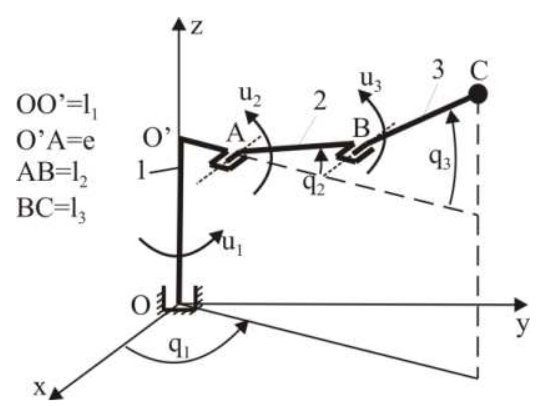

Fig. 1. The Scorbot-ER 4pc robotic manipulator (a), the scheme of the manipulator (b)

Theposition and velocity of the point $\mathrm{C}$ in the Cartesian coordinate system is expressed in the following way: 


$$
\begin{aligned}
& {\left[\begin{array}{l}
x_{C} \\
y_{C} \\
z_{C}
\end{array}\right]=\left[\begin{array}{l}
\left(e+l_{2} c_{2}+l_{3} c_{3}\right) c_{1} \\
\left(e+l_{2} c_{2}+l_{3} c_{3}\right) s_{1} \\
l_{1}+l_{2} s_{2}+l_{3} s_{3}
\end{array}\right]} \\
& {\left[\begin{array}{l}
v_{C x} \\
v_{C y} \\
v_{C z}
\end{array}\right]=\left[\begin{array}{ccc}
-\left(e+l_{2} c_{2}+l_{3} c_{3}\right) s_{1} & -l_{2} s_{2} c_{1} & -l_{3} s_{3} c_{1} \\
\left(e+l_{2} c_{2}+l_{3} c_{3}\right) c_{1} & -l_{2} s_{2} s_{1} & -l_{3} s_{3} s_{1} \\
0 & l_{2} c_{2} & l_{3} c_{3}
\end{array}\right]\left[\begin{array}{l}
\dot{q}_{1} \\
\dot{q}_{2} \\
\dot{q}_{3}
\end{array}\right]}
\end{aligned}
$$

where: $x_{C}, y_{C}, z_{C}$ - coordinates of point $\mathrm{C}, v_{C x}, v_{C y}, v_{C z}$ - projections of velocity of point $\mathrm{C}, e, l_{j}$ - geometrical parameters $(j=1,2,3), s_{j}=\sin q_{j}, c_{j}=\cos q_{j}$ - translation matrix of $a_{i}$ distance along axis $x, \dot{q}_{j}-$ the angular velocity of $j$-th links.

In a practical task, the desired path and velocity of point $\mathrm{C}$ in a workspace is defined, the projections of velocity may be calculated. Then, based on the eq. (2), a desired trajectory in a joint space may be determined, by solving the inverse kinematics problem. The dynamics of the Scorbot-ER 4pc manipulator can be expressed in the Lagrange form $[1,3,9]$ :

$$
\mathbf{M}(\mathbf{q}) \ddot{\mathbf{q}}+\mathbf{C}(\mathbf{q}, \dot{\mathbf{q}}) \dot{\mathbf{q}}+\mathbf{F}(\dot{\mathbf{q}})+\mathbf{G}(\mathbf{q})+\boldsymbol{\tau}_{d}=\mathbf{u}
$$

where: $\mathbf{q}$ - a vector of generalized coordinates (angles of rotation of links), $\mathbf{M}(\mathbf{q})$ - the inertia matrix, $\mathbf{C}(\mathbf{q}, \dot{\mathbf{q}}) \dot{\mathbf{q}}$ - the centrifugal and Coriolis vector, $\mathbf{F}(\dot{\mathbf{q}})$ - the friction vector, $\mathbf{G}(\mathbf{q})$ - the gravity vector, $\boldsymbol{\tau}_{d}$ - a vector of disturbances bounded by $\left\|\tau_{d}\right\|<b, b>0, \mathbf{u}-$ control input vector.

The mathematical model holds standard properties of revolute rigid manipulator dynamics [1]. Matrixes in the eq. (3) have the following form [9]:

$$
\begin{aligned}
& \mathbf{M}(\mathbf{q})=\left[\begin{array}{ccc}
M_{11} & 0 & 0 \\
0 & p_{6} & l_{2} p_{2} \cos \left(q_{3}-q_{2}\right) \\
0 & l_{2} p_{2} \cos \left(q_{3}-q_{2}\right) & p_{7}
\end{array}\right] \\
& \left.\mathbf{C}(\mathbf{q}, \dot{\mathbf{q}})=\left[\begin{array}{ccc}
a \dot{q}_{2}+b \dot{q}_{3} & a \dot{q}_{1} & b \dot{q}_{1} \\
-a \dot{q}_{1} & 0 & -c \dot{q}_{3} \\
-b \dot{q}_{1} & c \dot{q}_{2} & 0
\end{array}\right], \mathbf{F}(\dot{\mathbf{q}})=\left[\begin{array}{c}
p_{8} \dot{q}_{1}+p_{11} \operatorname{sgn}\left(\dot{q}_{1}\right) \\
p_{9} \dot{q}_{2}+p_{12} \operatorname{sgn}\left(\dot{q}_{2}\right) \\
p_{10} \dot{q}_{3}+p_{13} \operatorname{sgn}\left(\dot{q}_{3}\right)
\end{array}\right]\right\} \\
& \mathbf{G}(\mathbf{q})=\left[\begin{array}{lll}
0 & p_{1} g c_{2} & p_{2} g c_{3}
\end{array}\right]^{T}, \quad \mathbf{q}=\left[\begin{array}{lll}
q_{1} & q_{2} & q_{3}
\end{array}\right]^{T} \\
& \boldsymbol{\tau}_{d}(t)=\left[\begin{array}{lll}
\tau_{d 1}(t) & \tau_{d 2}(t) & \tau_{d 3}(t)
\end{array}\right]^{T}, \quad \mathbf{u}=\left[\begin{array}{lll}
u_{1} & u_{2} & u_{3}
\end{array}\right]^{T}
\end{aligned}
$$

where 


$$
\begin{aligned}
& M_{11}=2 p_{1} e c_{2}+2 p_{2}\left(e+l_{2} c_{2}\right) c_{3}+0.5 p_{3} \cos \left(2 q_{2}\right)+0.5 p_{4} \cos \left(2 q_{3}\right)+p_{5} \\
& a=-\left[p_{1} e s_{2}+p_{2} l_{2} s_{2} c_{3}+0.5 p_{3} \sin \left(2 q_{2}\right)\right] \\
& b=-\left[p_{2}\left(e+l_{2} c_{2}\right) s_{3}+0.5 p_{4} \sin \left(2 q_{3}\right)\right] \\
& c=l_{2} p_{2} \sin \left(q_{3}-q_{2}\right)
\end{aligned}
$$

Parameters $p_{i}$ take the form:

$$
\left.\begin{array}{rl}
p_{1}= & l_{c 2} m_{2}+l_{2} m_{3}+l_{2} m_{C} \\
p_{2} & =l_{c 3} m_{3}+l_{3} m_{C} \\
p_{3}= & l_{c 2}^{2} m_{2}+l_{2}^{2} m_{3}+l_{2}^{2} m_{C}-I_{2 x x}+I_{2 y y} \\
p_{4}= & l_{c 3}^{2} m_{3}+l_{3}^{2} m_{C}-I_{3 x x}+I_{3 y y} \\
p_{5}= & 0.5\left(I_{2 x x}+I_{2 y y}+I_{3 x x}+I_{3 y y}\right)+I_{1 z z}+\left(e^{2}+0.5 l_{c 2}^{2}\right) m_{2}+ \\
& +\left(e^{2}+0.5 l_{2}^{2}+0.5 l_{c 3}^{2}\right) m_{3}+\left(e^{2}+0.5 l_{2}^{2}+0.5 l_{3}^{2}\right) m_{C} \\
p_{6}= & l_{c 2}^{2} m_{2}+l_{2}^{2} m_{2}+l_{2}^{2} m_{C}+I_{2 z z} \\
p_{7}= & l_{c 3}^{2} m_{3}+l_{3}^{2} m_{C}+I_{3 z z} \\
p_{8}= & f_{1} \\
p_{9}= & f_{2} \\
p_{10}= & f_{3} \\
p_{11}= & \kappa_{1} \\
p_{12}= & \kappa_{2} \\
p_{13}= & \kappa_{3}
\end{array}\right\}
$$

where: $m_{j}-$ a mass of $j$-th link, $m_{C}-$ a mass of a gripper, $l_{j}$ - the length of $j$-th link, $l_{C j}$ - the distance between the center of mass of $j$-th link and joint $j-1$, $e$ - an eccentric of the second joint, $I_{j x x}, I_{j y y}, I_{j z z}$ - are mass moments of inertia of $j$-th link with respect to $x_{j}, y_{j}, z_{j}$ axis, respectively, $f_{j}-$ a coefficient of viscous friction in $j$-th kinematic pair, $\kappa_{j}-$ a moment of dry friction in $j$-th kinematic pair.

\section{Adaptive tracking control}

Assumed that the desired trajectory of the manipulator motion in the joint space is known. The desired trajectory $\mathbf{Q}_{d}$ consists of generalized coordinates $\mathbf{q}_{d}(t)=\left[q_{d 1}(t) q_{d 2}(t) q_{d 3}(t)\right]^{T}$ and the first and second time derivatives, i.e. $\mathbf{Q}_{d}=\left[\begin{array}{lll}q_{d}^{T} & \dot{q}_{d}^{T} & \ddot{q}_{d}^{T}\end{array}\right]^{T}$. The tracking control is defined in such a way, that for the desired trajectory the tracking error is introduced [1-3, 5-7]:

$$
\mathbf{e}(t)=\mathbf{q}_{d}(t)-\mathbf{q}(t)
$$


The purpose of the control system is the realisation of such control signal $\mathbf{u}$, which will minimise the tracking error and will cause that $\mathbf{q}(t)$ will follows the $\mathbf{q}_{d}(t)$. Defined a filtered tracking error $\mathbf{s}$ and an auxiliary signal $\mathbf{v}$ as:

$$
\begin{aligned}
& \mathbf{s}=\dot{\mathbf{e}}+\Lambda \mathbf{e} \\
& \mathbf{v}=\dot{\mathbf{q}}_{d}+\Lambda \mathbf{e}
\end{aligned}
$$

where $\boldsymbol{\Lambda}$ - a diagonal positive definite design matrix.

The dynamics of the manipulator (eq. (3)) can be rewritten in terms of the filtered tracking error as:

$$
\mathbf{M}(\mathbf{q}) \dot{\mathbf{s}}=-\mathbf{u}-\mathbf{C}(\mathbf{q}, \dot{\mathbf{q}}) \mathbf{s}+\mathbf{f}+\boldsymbol{\tau}_{d}
$$

where $\mathbf{f}$ is a nonlinear manipulator function, which may be written in the linear parametric form as:

$$
\mathbf{f}=\mathbf{M}(\mathbf{q}) \dot{\mathbf{v}}+\mathbf{C}(\mathbf{q}, \dot{\mathbf{q}}) \mathbf{v}+\mathbf{F}(\dot{\mathbf{q}})+\mathbf{G}(\mathbf{q})=\mathbf{Y}_{v}(\mathbf{q}, \dot{\mathbf{q}}, \mathbf{v}, \dot{\mathbf{v}}) \mathbf{p}
$$

where $\mathbf{Y}_{v}(\mathbf{q}, \dot{\mathbf{q}}, \mathbf{v}, \dot{\mathbf{v}}) \mathbf{p}$ - a regression matrix.

In standard use, in robotics it is a proportional-plus-derivative (PD) control law with nonlinearity compensation, given by the equation:

$$
\mathbf{u}=\mathbf{K}_{D} \mathbf{S}+\mathbf{Y}_{v}(\mathbf{q}, \dot{\mathbf{q}}, \mathbf{v}, \dot{\mathbf{v}}) \hat{\mathbf{p}}
$$

where term:

$$
\mathbf{K}_{D} \mathbf{s}=\mathbf{K}_{D}(\dot{\mathbf{e}}+\Lambda \mathbf{e})
$$

has a mathematical structure like a PD controller, and the term $\mathbf{Y}_{v}(\mathbf{q}, \dot{\mathbf{q}}, \mathbf{v}, \dot{\mathbf{v}}) \hat{\mathbf{p}}$ approximates nonlinear function $\mathbf{f}$. In control law (12) estimation $\widehat{\mathbf{p}}$ of a real vector $\mathbf{p}$ is used, because the real vector of parameters is unknown. The closedloop system becomes:

$$
\mathbf{M}(\mathbf{q}) \dot{\mathbf{s}}=-\mathbf{K}_{D} \mathbf{s}-\mathbf{C}(\mathbf{q}, \dot{\mathbf{q}}) \mathbf{s}+\mathbf{Y}_{v}(\mathbf{q}, \dot{\mathbf{q}}, \mathbf{v}, \dot{\mathbf{v}}) \tilde{\mathbf{p}}+\boldsymbol{\tau}_{d}
$$

where an estimation error is given by the equation:

$$
\tilde{\mathbf{p}}=\mathbf{p}-\hat{\mathbf{p}}
$$

A scheme of closed-loop system is presented in fig. 2. 


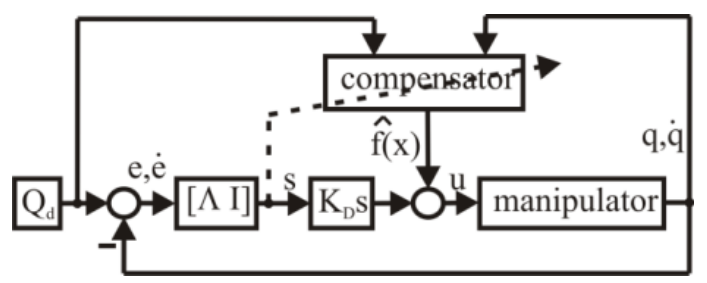

Fig. 2. Schematic structure of the adaptive control system

In order to derive adaptation law of the parameters, the Lyapunov stability theory is applied. We assumed the positive definite Lyapunov function candidate, which is a quadratic form of the filtered tracking error and the parameter estimation error [2]:

$$
L=0.5 \mathbf{s}^{T} \mathbf{M}(\mathbf{q}) \mathbf{s}+0.5 \tilde{\mathbf{p}}^{T} \boldsymbol{\Gamma}_{p}^{-1} \tilde{\mathbf{p}}
$$

where: $\boldsymbol{\Gamma}_{p}-$ a regression matrix.

Time derivative of $L$ is:

$$
\dot{L}=\mathbf{s}^{T} \mathbf{M}(\mathbf{q}) \dot{\mathbf{s}}+0.5 \mathbf{s}^{T} \dot{\mathbf{M}}(\mathbf{q}) \mathbf{s}+\tilde{\mathbf{p}}^{T} \boldsymbol{\Gamma}_{p}^{-1} \dot{\tilde{\mathbf{p}}}
$$

Substituting eq. (14) into eq. (17), and taking into account, that $\dot{\mathbf{M}}(\mathbf{q})-$ $2 \mathbf{C}(\mathbf{q}, \dot{\mathbf{q}})$ is a skew-symmetric matrix, we have:

$$
\dot{L}=-\mathbf{s}^{T} \mathbf{K}_{D} \mathbf{S}+\mathbf{s}^{T} \boldsymbol{\tau}_{d}+\tilde{\mathbf{p}}^{T}\left[\boldsymbol{\Gamma}_{p}^{-1} \dot{\tilde{\mathbf{p}}}+\mathbf{Y}_{v}(\mathbf{q}, \dot{\mathbf{q}}, \mathbf{v}, \dot{\mathbf{v}})^{T} \mathbf{s}\right]
$$

Defining an adaptive law as [10]:

$$
\dot{\hat{\mathbf{p}}}=\boldsymbol{\Gamma}_{p} \mathbf{Y}_{v}(\mathbf{q}, \dot{\mathbf{q}}, \mathbf{v}, \dot{\mathbf{v}})^{T} \mathbf{s}-k \boldsymbol{\Gamma}_{p}\|\mathbf{S}\| \hat{\mathbf{p}}
$$

where $k>0$, and taking into account, that the vector of the real parameters satisfies the constraint:

$$
\|\mathbf{p}\| \leq p_{\max }
$$

we may write $\dot{L}$ as:

$$
\dot{L}=-\mathbf{s}^{T} \mathbf{K}_{D} \mathbf{S}+\mathbf{s}^{T} \boldsymbol{\tau}_{d}+k\|\mathbf{s}\| \tilde{\mathbf{p}}^{T} \hat{\mathbf{p}}
$$

Because inequality: 


$$
\tilde{\mathbf{p}}^{T} \hat{\mathbf{p}} \leq\|\tilde{\mathbf{p}}\| p_{\max }-\|\tilde{\mathbf{p}}\|^{2}
$$

is true, so $\dot{L}$ satisfies the condition:

$$
\begin{aligned}
\dot{L} & \leq-\|\mathbf{s}\|\left[K_{D \text { min }}\|\mathbf{s}\|-b+k\|\tilde{\mathbf{p}}\|\left(\|\tilde{\mathbf{p}}\|-p_{\text {max }}\right)\right] \leq \\
& \leq-\|\mathbf{s}\|\left[K_{D \text { min }}\|\mathbf{s}\|-b+k\left(\|\tilde{\mathbf{p}}\|-0.5 p_{\text {max }}\right)^{2}-0.25 k p_{\text {max }}^{2}\right]
\end{aligned}
$$

Function $\dot{L} \leq 0$ if

$$
\|\mathbf{s}\|>\frac{b+0.25 k p_{\max }^{2}}{K_{D \min }} \equiv b_{s}
$$

or

$$
\|\tilde{\mathbf{p}}\|>0.5 p_{\max }+\sqrt{\frac{b}{k}+0.25 p_{\max }^{2}} \equiv b_{p}
$$

where $K_{D \min }-$ is the minimum singular value of $\mathbf{K}_{D}$.

This result means, that the time derivative of the function $L$ along the solutions of the eq. (14) is negative outside a compact set. The adaptive law (19) guarantees that estimates of parameters will be bounded without persistency of the excitation condition. According to a standard Lyapunov theorem extension [10], both $\|\mathbf{s}\|$ and $\|\tilde{\mathbf{p}}\|$ are uniformly ultimately bounded.

\section{Experimental results}

In order to confirm the behaviour of the proposed adaptive control system, an experiment was performed. The workstation consists of the Scorbot-ER 4pc robotic manipulator, PC computer with Matlab and dSPACE ControlDesk software, and DS1006 digital signal processing board.

In the experiment, the point $\mathrm{C}$ of the manipulator has moved on a desired circular path (fig. 3a), defined in the following way:

$$
\left.\begin{array}{l}
\left(x_{C}-x_{O}\right)^{2}+\left(y_{C}-y_{O}\right)^{2}-R^{2}=0 \\
z_{C}=\text { const. }
\end{array}\right\}
$$

where: $x_{O}=0.36 \mathrm{~m}, y_{O}=0 \mathrm{~m}-$ coordinates of the center of the circle.

Desired velocity of the point $\mathrm{C}$ (fig. $3 \mathrm{~b}$ ) is given by the equation: 


$$
v_{C}=-v_{\max } \sum_{i=1}^{12} \frac{(-1)^{i}}{1+\exp \left[-c\left(t-t_{i}\right)\right]}, \quad i=1,2, \ldots, 12
$$

where: $v_{\max }=0.12 \mathrm{~m} / \mathrm{s}-$ a maximal velocity, $c=101 / \mathrm{s}-$ a design coefficient, $t \in\langle 0-65\rangle \mathrm{s}-$ the time, $t$ - coefficients selected in accordance with rule $t_{i-1}<t_{i}$.
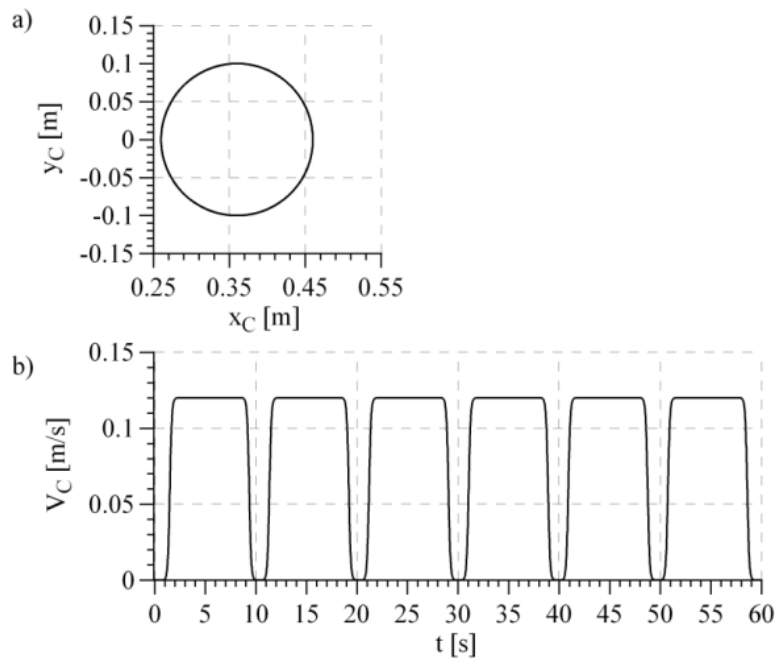

Fig. 3. The desired path (a), the desired velocity of the point $C$ (b)

The desired trajectory in a joint space was obtained by solving the inverse kinematics problem for the desired path and velocity. This trajectory is shown in fig. 4. During the experiment, the gripper of the manipulator (point $C$ ) was loaded in the following way: for time $t<30 \mathrm{~s}$ the gripper was loaded by an additional mass, which was equal to $0.75 \mathrm{~kg}$, and for $t \geq 30 \mathrm{~s}$ the additional mass was increased to $2.5 \mathrm{~kg}$. Design parameters in the control system were assumed as follows: $\mathbf{K}_{D}=\operatorname{diag}\left\{\begin{array}{lll}0.5 & 0.5 & 0.5\end{array}, \boldsymbol{\Lambda}=\operatorname{diag}\{222, \hat{\mathbf{p}}(0)=\mathbf{0}, \quad k=0.1, \boldsymbol{\Gamma}=\right.$

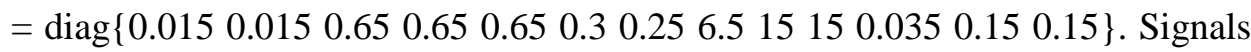
generated by the control system during the experiment are shown in fig. 5 .

At the beginning of the experiment, signals generated by compensator (fig. 5c) were not accurate, because the initial parameter estimates were set to zero, and the signals generated by the PD controller (fig. 5b) take an important part in the total control signals (fig. 5a). Then, the influence of PD signals decreases during the experiment, because the parameter estimates adaptation.

In the initial movement phase (about $8 \mathrm{~s}$ ), tracking errors of joint angles (fig. 6a) and tracking errors of angular velocities (fig. 6b) have the highest values. Afterwards they are decreased during the adaptation of parameter estimates. After $30 \mathrm{~s}$ of the experiment, tracking errors temporarily increased. It is caused 
by the change of the gripper load. Then, tracking errors are reduced during adaptation of control system to the new working conditions.
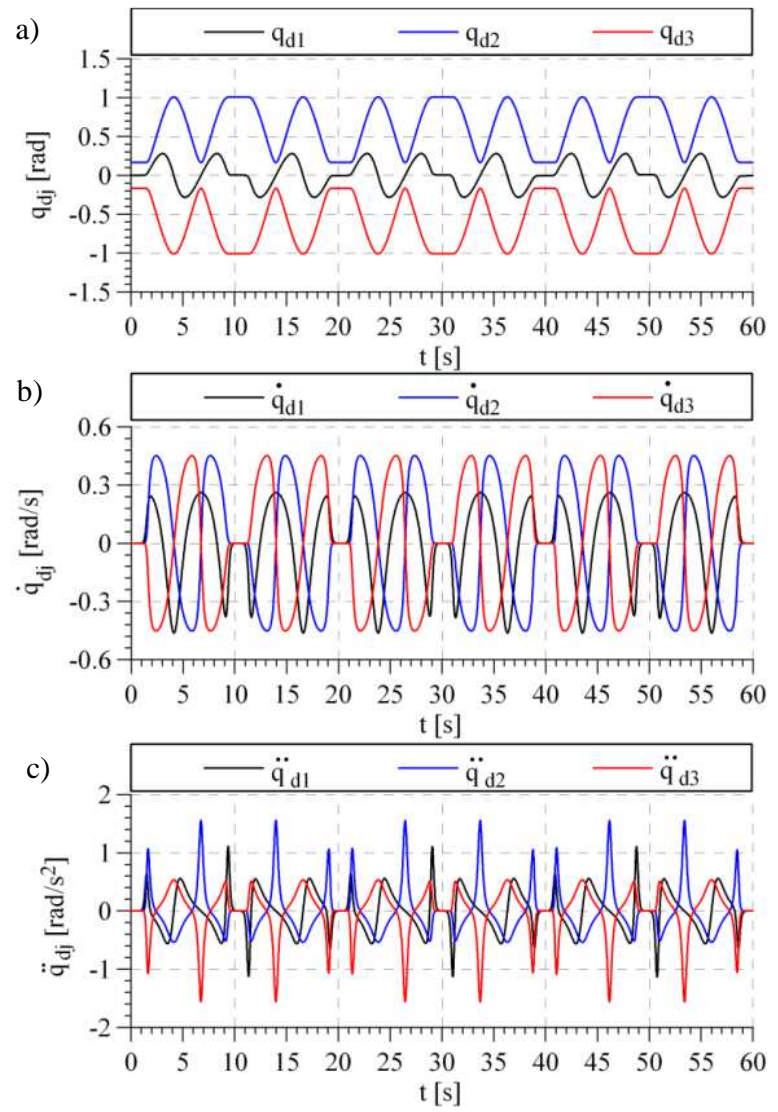

Fig. 4. The desired trajectory in a joint space: a) angles of rotation of links 1, 2, 3, b) angular velocities of links 1,2, 3, c) angular accelerations of links 1, 2, 3

In figure 7. estimated characteristics of parameters are shown. They were set to zero in the initialization process, and adapted during the movement of the manipulator. After $30 \mathrm{~s}$, values of parameters estimates change, which is caused by change of working conditions. In figure 8 . real path (fig. $8 \mathrm{a}$ ) and velocity of point $\mathrm{C}$ (fig. $8 \mathrm{~b}$ ) are shown.

In the initial movement phase, the real path and velocity of point $\mathrm{C}$ differs from the desired, later they near the desired path and velocity.

In the second experiment we set up non-zero values of parameter estimates - we used final values from the first experiment. In this case, the compensator generated adequate signals even in the initial movement phase, and tracking 

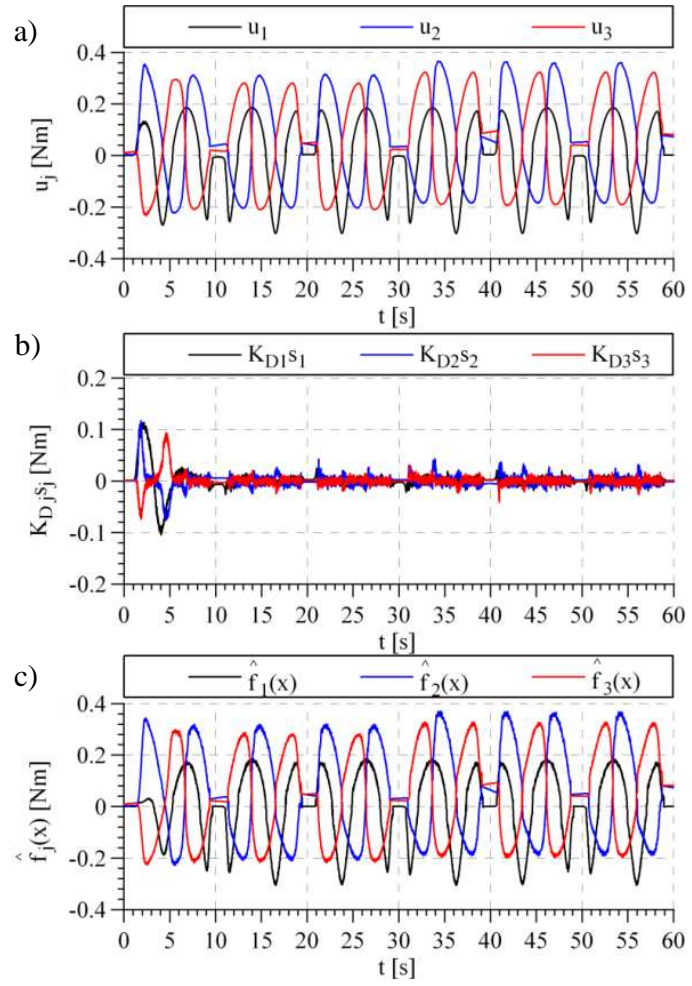

Fig. 5. Control signals: a) total control signals, b) signals generated by the PD controller, c) signals generated by compensator
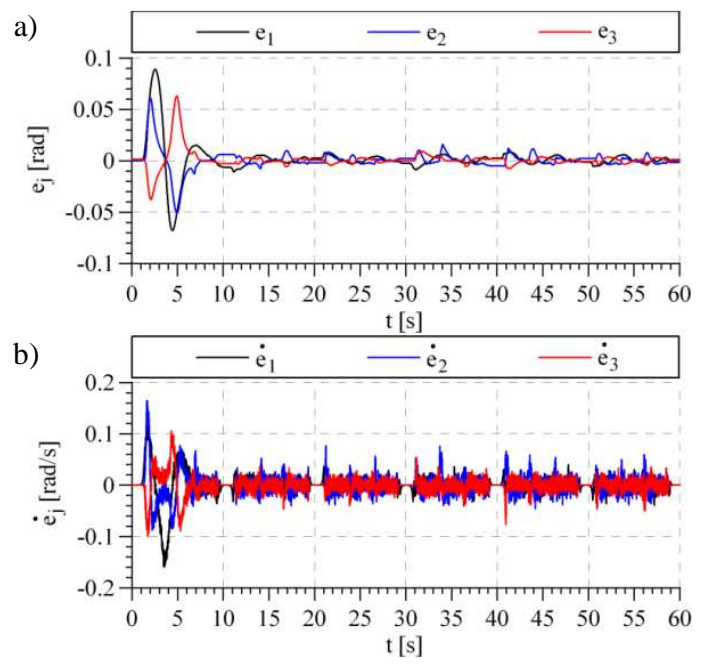

Fig. 6. Tracking errors: a) tracking errors of joint angles, b) tracking errors of angular velocities 

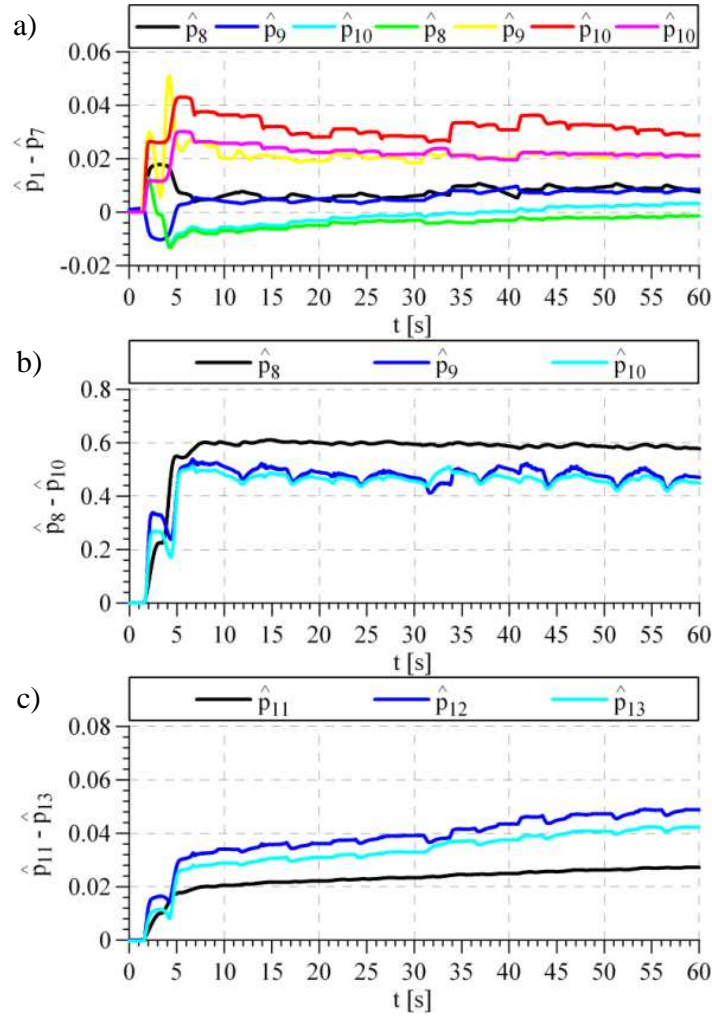

Fig. 7. Estimated characteristics of parameters: a) $\hat{p}_{1}-\hat{p}_{7}$, b) $\hat{p}_{8}-\hat{p}_{10}$, c) $\hat{p}_{11}-\hat{p}_{13}$

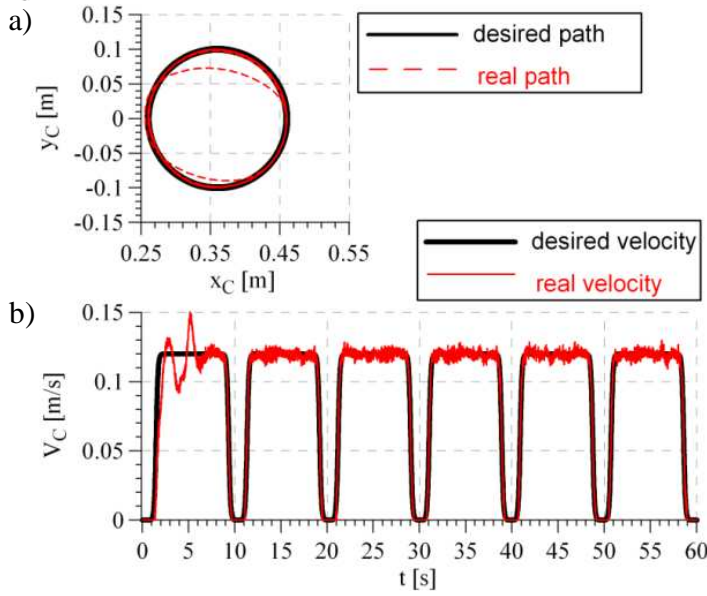

Fig. 8. Performance of movement in a workspace: a) the desired (black line) and the real (red line) path of point $\mathrm{C}, \mathrm{b}$ ) the desired (black line) and the real (red line) velocity of point $C$ 
errors (fig. 9.) were smaller than in the first experiment. In the workspace, precision of movement was also higher, so the real path and velocity (fig. 10.) were close to the desired path and velocity of point $\mathrm{C}$, even in initial phase of experiment.
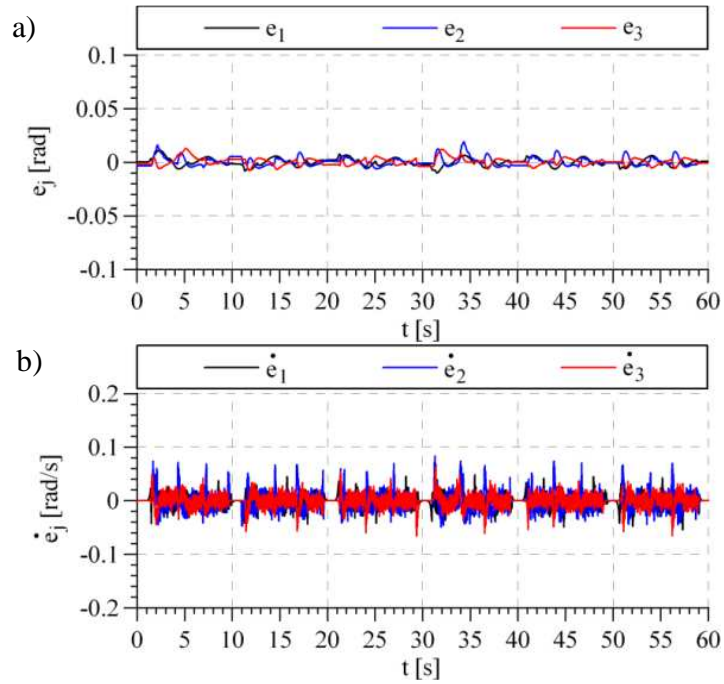

Fig. 9. Tracking errors from an experiment with nonzero values of parameter estimates: a) tracking errors of joint angles, b) tracking errors of angular velocities
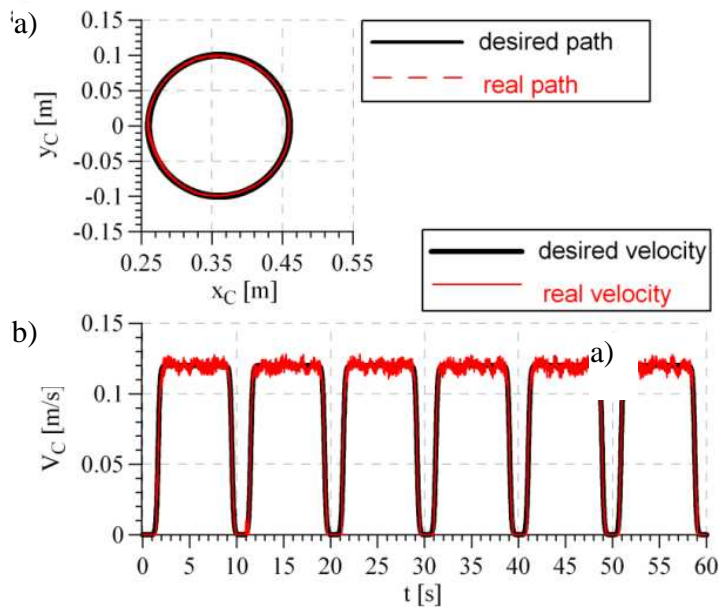

Fig. 10. Performance of movement in a workspace from an experiment with non-zero values of parameter estimates: a) the desired (black line) and the real (red line) path of point $\mathrm{C}, \mathrm{b}$ ) the desired (black line) and the real (red line) velocity of point $\mathrm{C}$ 
In order to compare adaptive control with the computed torque method, we assumed the following control law:

$$
\mathbf{u}=\mathbf{M}(\mathbf{q})\left(\ddot{\mathbf{q}}_{d}+\mathbf{K}_{1} \dot{\mathbf{e}}+\mathbf{K}_{0} \mathbf{e}\right)+\mathbf{C}(\mathbf{q}, \dot{\mathbf{q}}) \dot{\mathbf{q}}+\mathbf{F}(\dot{\mathbf{q}})+\mathbf{G}(\mathbf{q})
$$

where: $\mathbf{K}_{0}=\operatorname{diag}\{225225225\}-$ the matrix of the proportional gain, $\mathbf{K}_{1}=$ $=\operatorname{diag}\left\{\begin{array}{llll}30 & 30 & 30\end{array}\right\}-$ the matrix of the derivative gain.

Matrixes $\mathbf{M}(\mathbf{q}), \mathbf{C}(\mathbf{q}, \dot{\mathbf{q}}), \mathbf{F}(\dot{\mathbf{q}})$, and $\mathbf{G}(\mathbf{q})$ have nominal parameters: $p_{1}=$ $=p_{4}=p_{7}=0.006, p_{2}=0.002, p_{3}=p_{5}=p_{6}=0.011, p_{8}=p_{9}=p_{10}=0.52, p_{11}=$ $=0.019, p_{12}=p_{13}=0.018$. Tracking errors, obtained in this case, are presented in fig. 11.

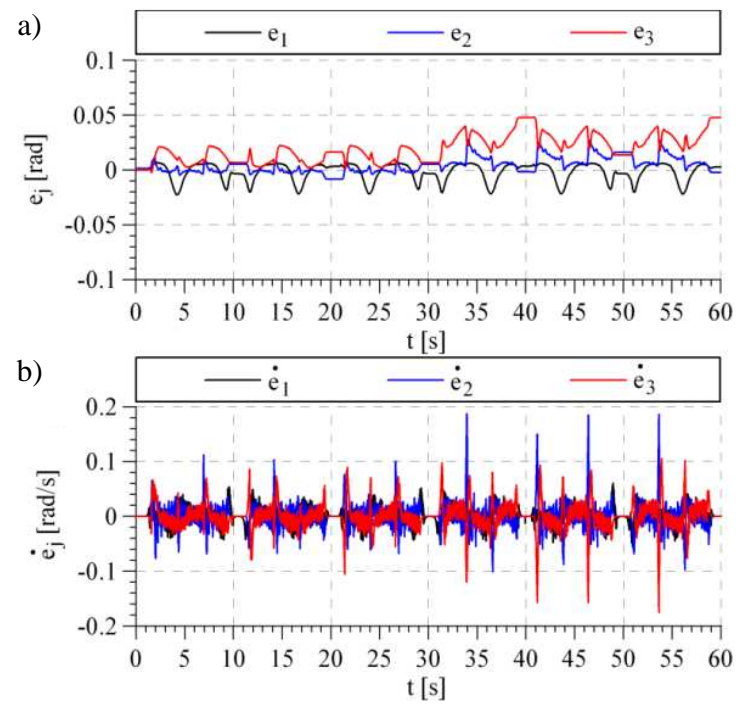

Fig. 11. Tracking errors from an experiment with the computed torque method: a) tracking errors of joint angles, b) tracking errors of angular velocities

After $30 \mathrm{~s}$ tracking errors of links 2 and 3 have increased, because the gripper load changed, but parameters in the compensator were constant. In figure 12. path and velocity in the workspace of point $\mathrm{C}$ are presented.

\section{Conclusions}

For numerical evaluation of the adaptive control system quality, we used a root mean square of tracking errors (tab. 1.), defined as: 


$$
\left\{\begin{array}{l}
\varepsilon_{j}=\sqrt{\frac{1}{n} \sum_{k=1}^{n} e_{j k}^{2}} \\
\psi_{j}=\sqrt{\frac{1}{n} \sum_{k=1}^{n} \dot{e}_{j k}^{2}}
\end{array}\right.
$$

where: $k$-an index of sample, $n-$ a number of sample.
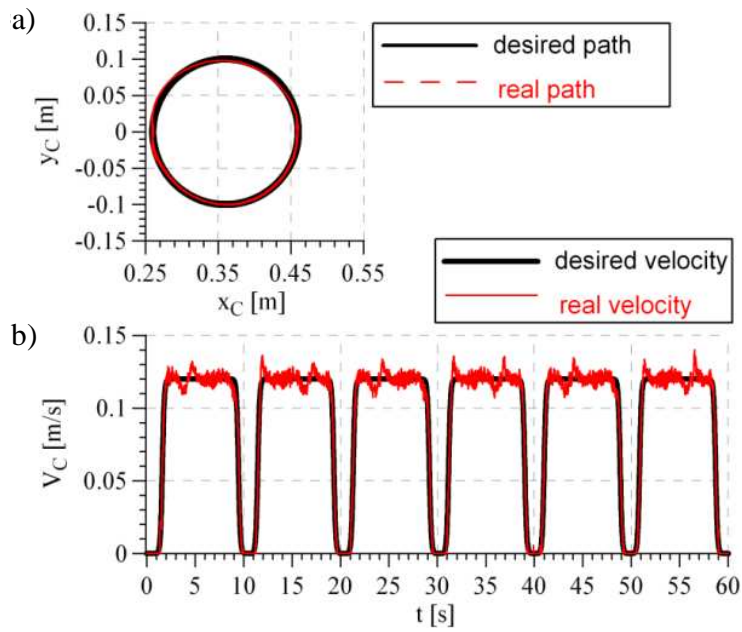

Fig. 12. Performance of movement in a workspace from an experiment with the computed torque method desired (black line) and the real (red line): a) the path of point $\mathrm{C}$, b) the velocity of point $\mathrm{C}$

Table 1 . Values of quality ratings

\begin{tabular}{|c|c|c|c|}
\hline Parameter & $\boldsymbol{j}$ & $\boldsymbol{\varepsilon}_{\boldsymbol{j}}$ & $\boldsymbol{\psi}_{\boldsymbol{j}}$ \\
\hline \multirow{3}{*}{ Adaptive control } & 1 & 0.0158 & 0.0228 \\
\cline { 2 - 4 } & 2 & 0.0095 & 0.0204 \\
\cline { 2 - 4 } & 3 & 0.0088 & 0.0164 \\
\hline \multirow{2}{*}{$\begin{array}{c}\text { Adaptive control } \\
\text { (non-zero parameters) }\end{array}$} & 1 & 0.0036 & 0.0104 \\
\cline { 2 - 4 } & 2 & 0.0041 & 0.0162 \\
\hline \multirow{3}{*}{ Computed torque } & 1 & 0.0035 & 0.0122 \\
\cline { 2 - 4 } & 2 & 0.0084 & 0.0152 \\
\cline { 2 - 4 } & 3 & 0.0233 & 0.0221 \\
\hline
\end{tabular}

The tracking control of the manipulator is problematic because of the nonlinearities. The most commonly usedtorque computing method requires a precise 
knowledge about the mathematical model structure of the control object and also the values of the parameters. In practical applications, while parameters of an object may change, this approach is ineffective. In this case, the adaptive control system, with pre-adapted parameters ensures better quality of tracking control. In both algorithms, the structure of the mathematical model must be known.

\section{References}

[1] Canudas de Wit C., Siciliano B., Bastin G.: Theory of Robot Control. Springer-Verlag, London 1996.

[2] Spong M.W., Vidyasagar M.: Dynamika i sterowanie robotów. WNT, Warszawa 1997.

[3] Tchoń K. i in.: Manipulatory i roboty mobilne: modele, planowanie ruchu i sterowanie. Akademicka Oficyna Wydawnicza PLJ, Warszawa 2000.

[4] Cazilla J., Vallés M., Mata V., Díaz-Rodríguez M., Valera A.: Adaptive control of a 3-DOF parallel manipulator considering payload handling and relevant parameter models. Robot. Computer-Integrated Manuf., 30 (2014), 468-477.

[5] Giergiel M.J., Hendzel Z., Żylski W.: Modelowanie i sterowanie mobilnych robotów kołowych. PWN, Warszawa 2002.

[6] Isidori A.: Nonlinear Control Systems: An Introduction. Springer-Verlag, Berlin 1985.

[7] Slotine J.J., Li W.: Applied Nonlinear Control. Prentice Hall, New Jersey 1991.

[8] Zeinali M., Notash L.: Adaptive sliding mode control with uncertainty estimator for robot manipulators. Mech. Machine Theory, 45 (2010), 80-90.

[9] Żylski W., Gierlak P.: Modelowanie ruchu wybranego manipulatora. Acta Mech. Automatica, 4 (2010), 112-119.

[10] Lewis F.L., Yesildirek A., Liu K.: Multilayer Neural-Net Robot Controller with Guaranteed Tracking Performance. IEEE Trans. Neural Networks, 7 (1996), 388-399 .

\section{ADAPTACYJNE STEROWANIE MANIPULATOREM SCORBOT-ER 4PC}

\section{Streszczenie}

Sterowanie ruchem nadążnym manipulatora nie jest prostym zagadnieniem, ponieważ manipulator jest nieliniowym obiektem, którego parametry mogą być nieznane i zmienne. Prawo sterowania powinno uwzględniać te aspekty i umożliwiać manipulatorowi poprawne działanie nawet wtedy, gdy warunki jego pracy są zmienne. Wymaganie to jest spełnione przy zastosowaniu adaptacyjnych układów sterowania. W artykule przedstawiono równania kinematyki i dynamiczne równania ruchu manipulatora Scorbot-ER 4pc. Zaprezentowane prawa sterownia i adaptacji gwarantują praktyczną stabilność w sensie Lapunowa. W pracy zamieszczono rezultaty weryfikacji prezentowanych rozwiązań teoretycznych. Eksperymenty przeprowadzono na stanowisku, które składa się z robota manipulacyjnego Scorbot-ER 4pc, komputera PC z oprogramowaniem Matlab i dSPACE ControlDesk oraz karty kontrolno-pomiarowej DS1006. Podczas eksperymentów wybrany punkt manipulatora poruszał się po żądanym torze kołowym, a chwytak manipulatora był obciążany zmiennym ładunkiem. Działanie adaptacyjnego układu sterowania porównano z działa- 
niem układu z zaimplementowaną metodą wyliczanego momentu. Z porównania jakości sterowania wynika, że w praktyce lepsze wyniki zapewnia stosowanie sterowania adaptacyjnego.

Słowa kluczowe: robot manipulacyjny, dynamika manipulatora, adaptacyjny układ sterowania, stabilność w sensie Lapunowa

DOI: $10.7862 / \mathrm{rm} .2014 .54$

Otrzymano/received: 2.07.2014 r.

Zaakceptowano/accepted: 12.11.2014 r. 